\title{
PENGARUH LEARNING CYCLE 5E BERBANTUAN PERMAINAN MONOPOLI FISIKA BERPOIN (MOKAIN) TERHADAP PENGUASAAN KONSEP PESERTA DIDIK SMA
}

\author{
Agus Budiyono, Moh. Afiful Hair, Arin Wildani, dan Firdausiyah \\ Universitas Islam Madura \\ e-mail: agusbudiyono@uim.ac.id
}

\begin{abstract}
Abstrak
Tujuan penelitian ini adalah mendeskripsikan dampak penggunaan permainan monopoli fisika berpoin pada model Learning Cycle 5E. Metode yang digunakan adalah kuasi eksperimen menggunakan desain kelas ekperimen dan kelas kontrol dengan pemberian tes awal dan tes akhir. Sampel diambil sebanyak dua kelas melalui metode purposive sampling sebanyak 35 peserta didik pada kelas eksperimen dan 35 peserta didik pada kelas kontrol. Data dikumpulkan menggunakan intrumen tes penguasaan konsep dan dampaknya dianalisis menggunakan effect size. Hasil penelitian menunjukkan penguasaan konsep peserta didik pada kelas eksperiman berada pada kategori sedang, yaitu sebesar 0,4 yang artinya $18 \%$ penguasaan konsep peserta didik dipengaruhi oleh model Learning Cycle 5E berbantuan permainan monopoli fisika berpoin, sedangkan penguasaan konsep peserta didik pada kelas kontrol berada pada kategori rendah, yaitu sebesar 0,1 yang berarti model Learning Cycle 5E tanpa berbantuan permainan monopoli fisika berpoin hanya berpengaruh sebesar $1 \%$. Penelitian ini dapat disimpulkan bahwa permainan monopoli fisika berpoin pada model pembelajaran Learning Cycle 5E berpengaruh positif terhadapa penguasaan konsep fisika peserta didik.
\end{abstract}

Kata Kunci: Model Learning Cycle 5E, Monopoli Fisika Berpoin, Penguasaan Konsep

\begin{abstract}
This study aims to describe the effect of using the physics monopoly game with points on the Learning Cycle 5E model. The method used quasi-experimental design using an experimental class and a control class with the provision of pre-test and post-test. Two classes of samples were taken through the purposive sampling method with 35 students in the experimental class and 35 students in the control class. The data were collected using a concept mastery test instrument and the effect was analyzed using the effect size. The results show that the students 'mastery of concepts in the experimental class is in the moderate category of 0.4 , which means that $18 \%$ of students' conceptual mastery is influenced by the game-assisted 5E Learning Cycle model with physics monopoly points, while the mastery of the concept of students in the control class is in the low category of 0.1 , which means that the $5 \mathrm{E}$ Learning Cycle model without the help of point-point physics monopoly games only affects $1 \%$. In a conclusion, physics monopoly game points on the Learning Cycle 5E model has a positive effect on students' mastery of physics concepts.
\end{abstract}

Keywords: Model of Learning Cycle 5E, Pointed Physics Monopoly, Concept Mastery 


\section{PENDAHULUAN}

Mata pelajaran fisika ditingkat SMA/MA menuntut peserta didik untuk mencapai kompetensi berupa penguasaan konsep. Peserta didik di SMA/MA hendaknya mampu menguasai pengetahuan sehingga dapat mengikuti pendidikan menengah secara optimal (Kemendikbud, 2016). Pembelajaran pada materi Fisika hendaknya dilakukan agar mampu menfasilitasi peserta didik dalam mencapai penguasaan konsep yang optimal (Saprudin, Liliasari, \& Prihatmanto, 2017; Abdurrahman, Saregar, \& Umam, 2018; Jamilah, Mulyaningsih, \& Bhakti, 2020). Penguasaan konsep peserta didik yang optimal dalam pembelajaran diharapkan dapat mengimplementasikan konsep fisika dalam kehidupan dan ativitas sehari-hari (Dewi, Suryadarma, \& Wilujeng, 2018; Wicaksono, 2020; Wilujeng, Suryadarma, \& Dwandaru, 2020). Penguasaan konsep peserta didik yang didapat dalam proses pelajaran fisika merupakan kemampuan dalam memahami konsep-konsep fisika setelah proses pembelajaran. Menurut Dahar (2011) bahwa memahami makna fisika secara ilmiah, baik penguasaan secara teori maupun kemampuan peserta didik dalam penerapkan konsep dalam keseharian merupakan bagian dari penguasaan konsep peserta didiksehingga peserta didik yang sudah mempelajari fisika diharapkan mampu menguasai konsep dari matei fisika yang telah diajarkan dan mampu menerapkannya dalam kehidupan sehari-hari. Pemahaman konsep terbangun dengan baik dengan adanya penerapan model pembelajaran (Chusni et al., 2018; Arifah \& Saefudin, 2017; Mardiana, Fitriani, \& Lesmana, 2018; Mei, Seto, \& Wondo, 2020).

Pembelajaran fisika hendaknya dijadikan lebih bermakna dan berkesan sebagai upaya untuk meningkatkan serta mengembangkan penguasaan konsep fisika pada peserta didik (Bergues, Casamayor, \& de la Arada, 2019; Hartini, Misbah, Helda, \& Dewantara, 2017; Nurhudayah, Lesmono, \& Subiki, 2017; Nasution, 2018). Adapun model pembelajaran yang mampu memberikan dampak terhadap penguasaan konsep peserta didik adalah model Learning Cycle 5E (Taufiq, Hindarto, \& Khumaedi, 2011; Wicaksono, Wazis, \& Madlazim, 2017). Model Learning Cycle 5E telah terbukti efektif untuk digunakan dalam pembelajaran fisika (Khan, Aurangzeb, \& Tahir, 2020; Fatimah, 2020; Haeroni, Susilawati, \& Rahayu, 2019; Putra et al., 2018; Hartini et al., 2017).

Pembelajaran fisika selain penggunaan model yang sejalan dengan upaya peningkatan penguasaan konsep fisika peserta didik, pembelajaran fisika juga perlu diintegrasikan dengan pembelajaran yang menyenangkan sehingga peserta didik merasa belajar fisika dengan santai dan asyik. Adapun pembelajaran yang dapat menghidupkan suasana belajar yang lebih bermakna adalah dengan menggunakan media educational game (Amory \& Seagram, 2003; Annetta, 2010; Denis \& Jouvelot, 2005; Suprapto, 2013; Widuri et al., 2019). educational game sangat berdampak jika digunakan dalam pelajaran fisika, sehingga peserta didik merasa senang dalam mempelajari fisika, lebih-lebih dalam 
pelaksanaan evaluasi pembelajaran, disisi lain dengan educational game peserta didik akan semakin termotivasi dalam mengikuti pelajaran fisika (Stage et al., 2011; Vos et al., 2011).

Monopoli fisika merupakan salah satu educational game yang bisa digunakan dalam pelajaran fisika utamanya dalam pelaksanaan evaluasi pembelajaran. Fitriyawany (2013); Ramadhani et al. (2016); Rofiqoh et al. (2015); Suprapto (2013) melaporkan bahwa permainan monopoli fisika dapat meningkatkan penguasaan konsep peserta didik. Sejalan dengan itu Arifin (2014); Purwanto et al. (2012) melaporkan bahwa kemampuan berpikir kritis peserta didik meningkat setelah peserta didik diberikan pembelajaran permainan monopoli fisika. Stage et al. (2011) melaporkan dengan pembelajaran berbasis serious game hasil belajar peserta didik di sekolah menengah di Belanda pada materi elektronika lebih baik dibandingkan dengan pembelajaran konvensional.

Pemberian permainan dalam Learning Cycle 5E adalah permainan monopoli fisika berpoin (MOKAIN). Permainan mokain ini dilaksanakan dalam fase Evaluation, yakni pada fase evaluation ini peserta didik diberikan permainan mokain sehingga peserta didik merasa tidak sedang dievaluasi namun peserta didik dilibatkan langsung dalam proses permainan berbasis evaluasi fisika. Peserta didik yang terlibat langsung dalam permainan mokain ini dapat memberikan dampak yang positif dalam ingatan peserta didik yang pada akhirnya dapat menguasai konsep fisika.

\section{METODE}

Metode yang digunakan pada penelitian ini adalah kuasi eksperimen dengan desain kelas eksperimen dan kelas kontrol mengacu Sugiono (2018) pada seperti ditunjukkan pada Gambar 1.

\begin{tabular}{|lccc|}
\hline Kelas & Pretest & Treatment & Posttest \\
Eksperimen & $\mathrm{O} 1$ & $\mathrm{X} 1$ & $\mathrm{O} 2$ \\
Kontrol & $\mathrm{O} 3$ & $\mathrm{X} 2$ & $\mathrm{O} 4$ \\
\hline
\end{tabular}

Gambar 1: Desain Penelitian

Keterangan:

O1 : Pretest penguasaan konsep kelas eksperimen

O2 : Pretest penguasaan konsep kelas kontrol

O3 : Posttetest penguasaan konsep kelas eksperimen

O4 : Posttetest penguasaan konsep kelas kontrol

X1 : Kelas eksperimen berupa model Learning Cycle 5E dengan MOKAIN

X2 : Kelas kontrol berupa model 5E tanpa MOKAIN 
Sampel diambil sebanyak dua kelas melalui metode purposive sampling sebanyak 35 peserta didik pada kelas kontrol dan 35 peserta didik pada kelas kontrol. Instrumen dalam penelitian adalah tes pengusaan konsep. Análisis data effect size dengan tujuan menghitung seberapa besar efek dari penggunaan mokain pada model Learning Cycle $5 E$ terhadapa penguasaan konsep peserta didik yang dihitung menggunakan persamaan (Field, 2009) dengan Persamaan (1).

$r=\frac{Z}{\sqrt{N}}$

Keterangan:

$r=$ Effect Size

$\mathrm{Z}=$ harga konversi dari standar deviasi

$\mathrm{N}=$ Jumlah Total Responden

Interpretasi data setelah diperoleh besar effect size dapat dijelaskan pada Tabel 1:

Tabel 1. Interpretasi Data

\begin{tabular}{ccc}
\hline $\mathrm{R}$ & $\%$ & Keterangan \\
\hline 0,10 & $1 \%$ & Kecil \\
0,30 & $9 \%$ & Sedang \\
0,50 & $25 \%$ & Besar \\
\hline
\end{tabular}

(Field, 2009)

\section{HASIL DAN PEMBAHASAN}

Penelitian ini menghasilkan data penguasaan konsep peserta didik yang diperoleh dari nilai tes baik sebelum pembelajaran maupun sesudah pembelajaran. Berdasarkan data tersebut dapat diurai dan dideskripsikan besar pengaruh model Learning Cycle $5 E$ berbantuan permainan MOKAIN dibandingkan dengan model Learning Cycle 5E saja. Adapun hasil analisis data pretest dan posttest ditunjukkan pada Tabel 2.

Tabel 2. Data Effect Size Kelas Ekperimen Dan Kelas Kontrol

\begin{tabular}{lccccc}
\hline Kelompok & $\mathrm{Z}$ & $\mathrm{N}$ & $\mathrm{r}=\frac{Z}{\sqrt{N}}$ & $\%=r^{2} \times 100 \%$ & Besar efek \\
\hline $\begin{array}{l}\text { Pretest } \\
\text { Eksperimen } \\
\text { dan kontrol }\end{array}$ & 0,857 & 58 & 0,1 & $1 \%$ & kecil \\
$\begin{array}{l}\text { Postest } \\
\text { eksperimen } \\
\text { dan kontrol }\end{array}$ & 3,197 & 58 & 0,4 & $18 \%$ & sedang \\
\hline
\end{tabular}

Tebel 2 menunjukkan bahwa besar effect size untuk kelas eksperimen sebesar 0,4 yang berarti dengan adanya permainan mokain pada model Learning Cycle $5 E$ memberikan pengaruh sebesar $18 \%$ terhadap penguasan konsep peserta didik atau berada pada kategori sedang. Sebaliknya pada kelas kontrol besar effect size adalah 0,1 yang berarti penguasaan konsep peserta didik pada model Learning Cycle 5E tanpa permainan mokain hanya memberikan pengaruh sebesar $1 \%$ terhadap penguasaan konsep peserta didik atau berada pada kategori rendah. 
Hasil data tersebut menunjukkan bahwa dengan pembelajaran menggunakan model Learning Cycle 5E dapat berdampak terhadap peningkatan penguasaan konsep peserta didik. Penelitian ini sejalan dengan penelitian (Wicaksono et al., 2017) bahwa model Learning Cycle $5 E$ mampu memberikan peningkatan penguasaan konsep peserta didik. Penelitian lain melaporkan penguasaan konsep peserta didik semakin meningkat setelah diberikan pembelajaran berupa model Learning Cycle 5E (Pratiwi, 2014). Penelitian ini membuktikan bahwa pembelajaran dengan model Learning Cycle $5 E$ memberikan pengalaman pembelajaran yang berorientasi pada penguasaan konsep peserta didik.

Model Learning Cycle 5E berbantuan permainan mokain mengalami penguasaan konsep yang lebih tinggi dibandingkan dengan model Learning Cycle $5 E$ tanpa berbantuan permainan mokain. Model Learning Cycle $5 E$ berbantuan mokain memberikan pengaruh sebesar $18 \%$ terhadap penguasaan peserta didik. Hal ini berbanding terbalik dengan model Learning Cycle 5E tanpa berbantuan mokain yang hanya memberikan pengaruh $1 \%$ terhadap penguasaan konsep peserta didik. Hal ini terlihat bahwa adanya permainan mokain ini dapat memberikan pengaruh yang besar terhadap penguasaan konsep peserta didik. Hasil ini sejalan dengan penelitian (Arifin, 2014; Irwan, 2017) yang melaporkan bahwa penguasaan konsep peserta didik menjadi lebih baik setelah diberikan permainan monopoli. Purwanto \& Annisa (2016) dan Ramadhani et al. (2016) juga melaporkan bahwa permainan monopoli memberikan dampak yang baik bagi penguasaan konsep peserta didik.

Permainan mokain dalam penelitian ini terdiri dari beberapa petak yaitu petak pertanyaan, petak perpustakaan, petak daya ingat serta petak hanya lewat. Petak pertanyaan dalam mokain ini berfungsi untuk memberikan pertanyaan yang selanjutnya dijawab oleh pemain, petak perpustakaan berfungsi untuk membuka kembali materi, petak daya ingat digunakan untuk pemilihan soal yang disediakan serta petak hanya lewat pemain hanya melewati petak tersebut. Jika pemain tidak mampu menjawab pertanyaan diperbolehkan membuka perpuatakaan dengan syarat membayar uang denda. Adapun gambar monopoli dan uang mainan fisika dalam penelitian ini dapat dilihat pada Gambar 2.

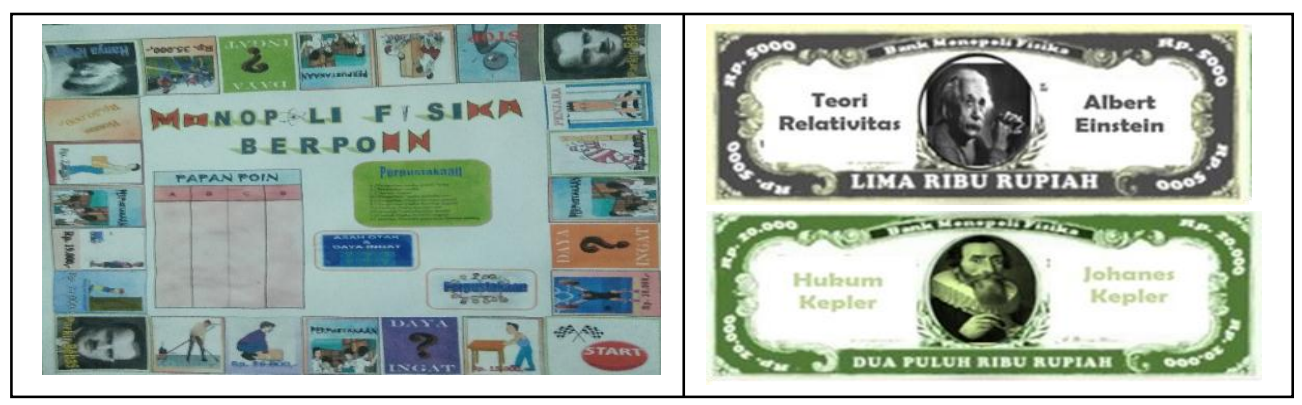

(a) (b)

Gambar 2. (a) Petak Monopoli Fisika, (b) Uang Monopoli Fisika 
Permainan mokain dalam penelitian disajikan dalam fase evaluation dari 5 fase pada Learning Cycle 5E. Dengan penyajian fase berbasis permainan ini menjadikan evaluasi terhadap proses pembelajaran peserta didik menjadi lebih menyenangkan. Peserta didik tidak merasa sedang diberikan evaluasi sehinga konsep yang sudah dikuasi akan mudah diingat dan bertahan lebih lama karena peserta didik langsung melakukan permainan.

Petak mokain yang memiliki fungsi seperti di atas terlihat bahwa mokain ini memberikan kesempatan kepada peserta didik untuk melatihkan daya ingat dalam konsep fisika yang sudah dipelajari. Disisi lain jika peserta didik mengalami kesulitan dalam menjawab pertanyaan, peserta didik diberi kesempatan untuk membuka perpustakaan mokain, dengan membuka perpustakaan tersbut peserta didik diharapkan dapat mengingat kembali materi yang sudah diajarkan sehingga pada petak pertanyaan dan petak daya ingat selanjutnya peserta didik mampu memberikan jawaban sehingga di akhir pembelajaran semua peserta didik mengalami peningkatan penguasaan konsep yang dipelajari. Adapun permainan mokain dapat diperlihatkan pada Gambar 3.

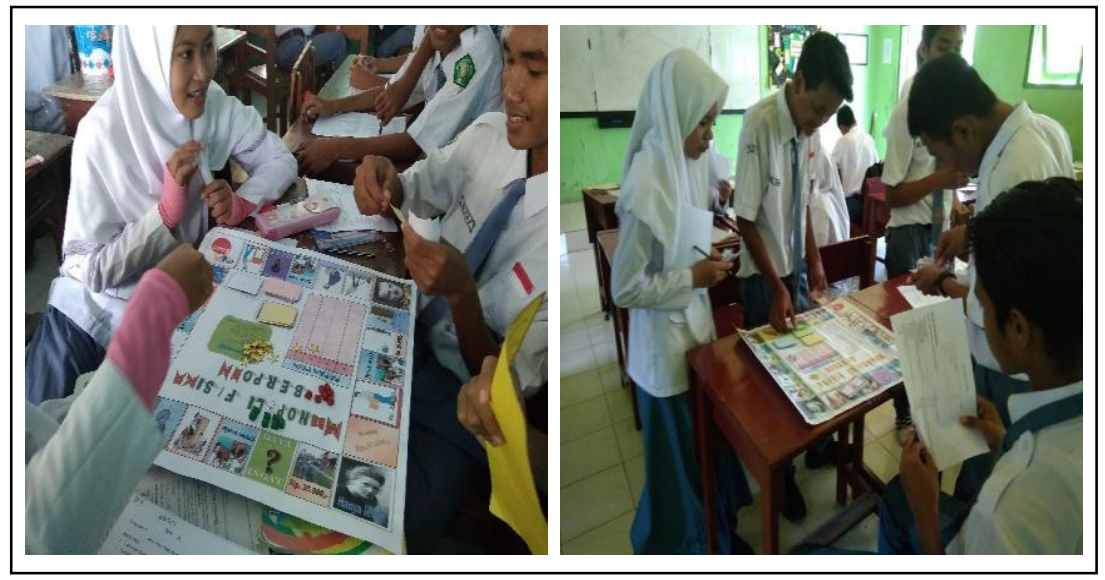

Gambar 3. Peserta Didik Sedang Bermain MOKAIN

Gambar 3 menunjukkan bahwa peserta didik begitu menikmati proses evaluasi yang dilaksanakan melalui permainan. Hal ini yang tidak diberikan terhadap kelas kontrol yang berdampak pada besarnya pengaruh di kelas kontrol berada pada kategori kecil. Permainan semacam ini terbukti dapat memberikan penguasaan konsep peserta didik semakin baik (Ramadhani et al., 2016; Wicaksono, Wazis, et al., 2017).

Sejauh ini penelitian tentang permainan mopopoli masih digunakan pada pembelajaran yang berbasis game tournament, dan dilaksanakan pada tahapan turnamen kelas. Dengan adanya temuan ini menginformasikan bahwa permainan dalam pembelajaran dapat juga disajikan pada saat pembelajaran sehingga tahapan evaluasi kepada peserta didik dilaksanakan pada saat pembelajaran berlangsung. Melalui permainan dalam proses evaluasi pembelajaran dapat berdampak pada kondisi peserta didik yang tidak sedang dievaluasi. 


\section{SIMPULAN}

Hasil penelitian ini dapat disimpulkan bahwa peran permainan MOKAIN pada model Learning Cycle 5E dapat memberikan pengaruh yang sedang terhadap penguasaan konsep peserta didik. Besar effect size adalah 0,4 yang berarti $18 \%$ penguasaan konsep peserta didik dipengaruhi oleh permainan mokain. Dengan demikian permainan semacam ini sangat disarankan dalam proses pembelajaran utamanya pembelajaran fisika baik pembalajaran fisika berbasis turnamen maupun pembelajaran fisika berbasis evaluasi.

\section{DAFTAR PUSTAKA}

Abdurrahman, A., Saregar, A., \& Umam, R. 2018. The Effect of Feedback as Soft Scaffolding on Ongoing Assessment toward the Quantum Physics Concept Mastery of the Prospective Physics Teachers. Jurnal Pendidikan IPA Indonesia, 7(1), 41-47.

Amory, A., \& Seagram, R. 2003. Educational game Models: Conceptualization and Evaluation: the practice of Higher Education. South African Journal of Higher Education, 17(2), 206-217.

Annetta, L. A. 2010. The "I's" Have It: A Framework for Serious Educational Game Design. Review of General Psychology, 14(2), 105-113. https://doi.org/10.1037/a0018985

Arifah, U., \& Saefudin, A. A. 2017. Menumbuhkembangkan kemampuan pemahaman konsep matematika dengan menggunakan model pembelajaran guided discovery. Union: Jurnal Pendidikan Matematik, 5(3), 263-272.

Arifin, E. G. 2014. Penggunaan Permainan Monopoli Fisika dalam Pembelajaran Kooperatif Tipe Teams Games Tournament (TGT) Untuk Meningkatkan Kemampuan Berpikir Kritis Siswa. RADIASI: Jurnal Berkala Pendidikan Fisika, 4(1), 81-85.

Bergues, J. M., Casamayor, R., \& de la Arada, D. A. 2019. Procedure to Introduce the Concept of the Derivative from a Meaningful Learning Perspective. In EDULEARN19 Proceedings 11th International Conference on Education and New Learning Technologies Palma, Spain. 1-3 July, 2019 (pp. 2584-2587). IATED Academy.

Chusni, M. M., Sanjaya, M. R., Assani, Q. M., \& Suryani, R. 2018. Belajar dan Pembelajaran Fisika: Seri Peta Konsep, Bagan Konsep dan Peta Pikiran: Vol. I (N. Riyanto, Ed.; No. 1; Issue 1). Pelita Gemilang Sejahtera (PGS). http://digilib.uinsgd.ac.id/21901/

Dahar, R. W. 2011. Teori Belajar dan Pembelajaran. Erlangga.

Denis, G., \& Jouvelot, P. (2005). Motivation-driven Educational Game Design: Applying Best Practices to Music Education. Proceedings of the 2005 ACM SIGCHI International Conference on Advances in Computer Entertainment Technology, 462465. https://doi.org/10.1145/1178477.1178581.

Dewi, E. C., Suryadarma, I. G. P., \& Wilujeng, I. 2018. Using Video Integrated with Local Potentiality to Improve Students' Concept Mastery in Natural Science Learning. JPhCS, 1097(1), 012001. 
Fatimah, I. 2020. The development of Physics Learning Tools in Vocational High School Based Constructivism Approach Using Learning Cycle 5E Model. In Journal of Physics: Conference Series (Vol. 1481, No. 1, p. 012120). IOP Publishing.

Field, A. P. 2009. Discovering Statistics using SPSS. SAGE.

Fitriyawany, F. 2013. Penggunaan Media Permainan Monopoli Melalui Pembelajaran Kooperatif Pada Mahasiswa didik Fisika Fakultas Tarbiyahdengan Konsep Tata Surya. Jurnal IImiah Didaktika, 13(2). https://doi.org/10.22373/jid.v13i2.475

Haeroni, H., Susilawati, S., \& Rahayu, S. 2019. Remediasi Miskonsepsi Siswa Pada Materi Optik Dengan Teknik CRI Modifikasi Melalui Model Learning Cycle 5E. Jurnal Pendidikan Fisika dan Teknologi, 5(1), 91-99.

Hartini, S., Misbah, Helda, \& Dewantara, D. 2017. The effectiveness of physics learning material based on South Kalimantan local wisdom. In AIP Conference Proceedings (Vol. 1868, No. 1, p. 070006). AIP Publishing LLC.

Irwan, D. 2017. Pengembangan Media Permainan (Game) Monopoli Pada Pembelajaran Fisika Materi Besaran Dan Satuan Pada Tingkat Sekolah Menengah Pertama (SMP) (Doctoral dissertation, UIN Ar-RAniry Banda Aceh).

Jamilah, P. N., Mulyaningsih, N. N., \& Bhakti, Y. B. 2020. The Effect of Learning Start Learning Strategy with A Question (LSQ) on the Mastery of Physics Concepts. Bulletin of Educational Science and Technology, 1(1), 20-26.

Khan, K., Aurangzeb, W., \& Tahir, T. 2020. Effectiveness of 5es Learning Cycle Model on Students Learning in Physics at Secondary School Level in Pakistan. Global Social Sciences Review, 1, 469-478.

Kemendikbud. 2016. Peraturan Menteri Pendidikan dan Kebudayaan Nomor 22 Tahun 2016 Tentang Standar Proses Pendidikan Dasar dan Menengah. Kemendikbud.

Mardiana, D., Fitriani, R. S., \& Lesmana, A. 2018. Penerapan Model Pembelajaran Contextual Teaching and Learning Dalam Pembelajaran Matematika Terhadap Kemampuan Pemahaman Konsep Matematika Siswa Di Sekolah Dasar. Jurnal Silogisme: Kajian IImu Matematika dan Pembelajarannya, 3(3), 88-93.

Mei, M. F., Seto, S. B., \& Wondo, M. T. S. 2020. Pembelajaran Kontekstual Melalui Permainan Kelereng pada Siswa Kelas III SD Untuk Meningkatkan Pemahaman Konsep Perkalian. JUPIKA: Jurnal Pendidikan Matematika, 3(2), 61-70.

Nasution, S. W. R. 2018. Penerapan Model Inkuiri Terbimbing (Guided Inquiry) dalam Meningkatkan Kemampuan Berpikir Kritis pada Pembelajaran Fisika. Jurnal Education and Development, 3(1), 1-1.

Nurhudayah, M., Lesmono, A. D., \& Subiki, S. 2017. Penerapan Model Inkuiri Terbimbing (Guided Inquiry) dalam Pembelajaran Fisika SMA di Jember (Studi pada Keterampilan Proses Sains dan Keterampilan Berpikir Kritis). Jurnal Pembelajaran Fisika, 5(1), 82-88.

Pratiwi, N.W. 2014. Penerapan Model Pembelajaran Learning Cycle 5E pada Materi Fluida Statis Siswa Kelas X SMA. Inovasi Pendidikan Fisika, 3(2). 
Purwanto, M., Sari, I. M., \& Husna, H. N. 2012. Implementasi Permainan Monopoli Fisika Sebagai Media Pembelajaran dalam Pembelajaran Kooperatif Tipe TGT untuk Meningkatkan Prestasi Belajar dan Mengetahui Profil Kemampuan Berpikir Kritis Siswa SMP. Jurnal Pengajaran Matematika dan IImu Pengetahuan Alam, 17(1), 69. https://doi.org/10.18269/jpmipa.v17i1.241

Purwanto, P., \& Annisa, J. 2016. Pengaruh Model Pembelajaran Kooperatif Tipe Teams Games Tournament (TGT) Menggunakan Media Permainan Monopoli Terhadap Hasil Belajar Fisika Siswa pada Materi Fluida Statis. Jurnal Ikatan Alumni Fisika Universitas Negeri Medan, 2(2), 34-39. https://doi.org/10.24114/jiaf.v2i2.4368.

Putra, F., Nur Kholifah, I. Y., Subali, B., \& Rusilowati, A. 2018. 5e-learning Cycle Strategy: Increasing Conceptual Understanding and Learning Motivation. Jurnal IImiah Pendidikan Fisika Al-Biruni, 7(2), 171.

Ramadhani, N., Wahyuni, S., \& Handayani, R. D. 2016. Pengembangan Media Educational Game "Monopoli Fisika Asik (MOSIK)" Pada Mata Pelajaran IPA Di SMP. Jurnal Pembelajaran Fisika, 5(3), 235-245.

Rofiqoh, F., Mahardika, I. K., \& Yushardi, Y. 2015. Pengaruh Model Pembelajaran Kooperatif Tipe Numbered Heads Together (NHT) Disertai Media Monopoli Games Terintegrasi Pendekatan Problem Solving Pada Pembelajaran Fisika Di SMA. Jurnal Pembelajaran Fisika, 4(3), 198-203.

Saprudin, S., Liliasari, L., \& Prihatmanto, A. S. 2017. Pre-Service Physics Teachers' Concept Mastery and the Challenges of Game Development on Physics Learning. In Journal of Physics: Conference Series (Vol. 895, No. 1, p. 012109).

Stage, L., Van Lankveld, G., \& Spronck, P. 2011. Teaching High School Physics with a Serious Game. International Journal of Computer Science in Sport, 10, 1-12.

Sugiono. 2018. Metode Penelitian Kuantitatif, Kualitatif dan R\&D (9th Ed.). Alvabeta.

Suprapto, A. N. 2013. Permainan Monopoli Sebagai Media untuk Meningkatkanminat Belajar Tata Boga Di SMA. Jurnal IImiah Guru Caraka Olah Pikir Edukatif, O(1). https://journal.uny.ac.id/index.php/cope/article/view/2963

Taufiq, M., Hindarto, N., \& Khumaedi. 2011. Student's Science Misconceptions Concerning the State Changes of Water and Their Remediation Using Three Different Learning Models in Elementary School. Jurnal Pendidikan Fisika Indonesia, 7(2). https://doi.org/10.15294/jpfi.v7i2.1075

Vos, N., van der Meijden, H., \& Denessen, E. 2011. Effects of Constructing Versus Playing An Educational Game on Student Motivation and Deep Learning Strategy Use. Computers \& Education, 56(1), 127-137. https://doi.org/10.1016/j.compedu.2010.08.013

Wicaksono, I., Jatmiko, B., \& Prastowo, T. 2017. Pengembangan Perangkat Pembelajaran Fisika Model Learning Cycle 5e Untuk Meningkatkan Pemahaman Konsep Siswa pada Materi Fluida Statis. JPPS (Jurnal Penelitian Pendidikan Sains), 4(2), 518-524. 
Wicaksono, I., Wazis, \& Madlazim. 2017. The Effectiveness Of Virtual Science Teaching Model (VS-TM) To Improve Student's Scientific Creativity And Concept Mastery On Senior High School Physics Subject. Journal of Baltic Science Education, 16(4), 549561.

Wicaksono, I. 2020. Validity and Practicality of the Biotechnology Series Learning Model to Concept Mastery and Scientific Creativity. International Journal of Instruction, 13(3), 157-170.

Widuri, S., Mchusni, M., \& Yuningsih, E. K. (2019). Koflusa Learning Media for Static Fluid. Journal of Physics: Conference Series, 1175, 012181. https://doi.org/10.1088/1742$6596 / 1175 / 1 / 012181$.

Wilujeng, I., Suryadarma, I., \& Dwandaru, W. S. B. 2020. Local Potential Integrated Science Video to Improve SPS and Concept Mastery. International Journal of Instruction, 13(4). 